\title{
Americana-SP, uma história entre rios
}

\section{Americana-SP, a history between rivers}

Gabriela Simonetti Trevisan*

Elizabete Carla Guedes**:

Jefferson Luis Rodrigues Bocardi****

Mariana Spaulucci Feltrin ${ }^{* * * * * *}$

\section{Resumo}

A história da cidade de Americana, inspirada na obra de pesquisadores consagrados da região de Campinas, como Jolumá Brito e Celso Maria de Mello Pupo, é atrelada à Fazenda Salto Grande. A partir do plantio de cana-de-açúcar e, posteriormente, café e algodão, teria se dado a povoação da região entre os rios Atibaia e Jaguari, consolidando-se no final do século XVIII. Algumas questões, contudo, foram analisadas com profundidade, atentando-se para a construção de uma genealogia dos donos de terras na região, bem como das datas e demarcações geográficas. Neste sentido, a busca de fontes historiográficas permitiram abordar novas possibilidades sobre a história da cidade, como novos nomes e novas datas. Este estudo se propôs a seguir o percurso da construção da história da cidade, retomando documentos e buscando publicizar uma nova perspectiva para essa narrativa, embasando-se em uma pesquisa rigorosa feita pelos Historiadores Independentes de Carioba.

Palavras-chave: História Regional; Fazendas; Fontes Históricas.

\section{Abstract}

The history of the city of Americana, inspired by the work of renowned researchers from Campinas, such as Jolumá Brito and Celso Maria de Mello Pupo, is linked to Fazenda Salto Grande. From the planting of sugarcane, and subsequently coffee and cotton, the settlement of the region between the rivers Atibaia and Jaguari took place, consolidating in the late eighteenth century. Some issues, however, were analyzed in depth, focusing on the construction of a genealogy of landowners in the region, as well as dates and geographical demarcations. In this sense, the search for historiographical sources allowed us to approach new possibilities on the history of the city, such as new names and new dates. Thus, this study set out to follow the course of the construction of the city's history, retrieving documents and seeking to publicize a new perspective for this narrative, based on a rigorous research done by the Historiadores Independentes de Carioba.

Keywords: Regional History; Farms; Historical Sources.

\footnotetext{
* Mestranda em História pela Universidade Estadual de Campinas (Unicamp). Bolsista FAPESP.E-mail: trevisan.gabriela@gmail.com

** Formada em Licenciatura em História pelo Centro Universitário de Araras Dr. Edmundo Ulson (Unar). Estudante de bacharelado em Museologia pela Claretiano Campinas. Funcionária pública da Secretaria de Cultura e Turismo de Americana, coordenadora do Projeto Raízes e coordenadora do Museu Histórico e Pedagógico Dr. João da Silva Carrão (Museu Salto Grande). E-mail: carla.bellyguedes@gmail.com

**** Licenciado em História pela Universidade Metodista de Piracicaba (Unimep). Professor PEB II da Secretaria de Educação do Estado de São Paulo. E-mail: jlbocardi@yahoo.com

**:*: Licenciada em História pela Universidade Metodista de Piracicaba (Unimep). Professora do Ensino Fundamental II na rede privada de ensino.E-mail:mfeltrin@gmail.com
} 


\section{Dossiê}

\section{I
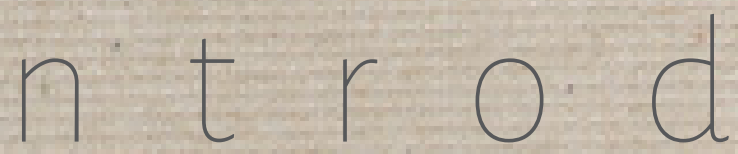 \\ U

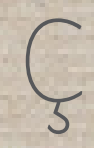 \\ $\tilde{a}$

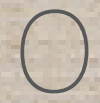

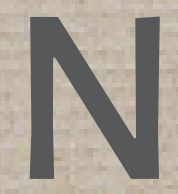

o início de 2017, quatro historiadores decidiram se unir para estudar a história da cidade de Americana, no interior do estado de São Paulo, formando o grupo Historiadores Independentes de Carioba. O município fica a aproximadamente quarenta quilômetros da atual Campinas, da qual foi comarca até 1924, e seu povoamento teria iniciado a partir das terras da Fazenda Salto Grande, localizada entre os rios Jaguari e Atibaia. No percurso de pesquisa, deparamo-nos com o desafio de buscar as fontes históricas pouco citadas nos trabalhos historiográficos locais.

Focados em um trabalho de história regional, percorremos, em especial, o Centro de Memória da Unicamp, em Campinas, e o Arquivo Público do Estado de São Paulo, preocupados com dois pontos: o primeiro - foco maior deste texto - foi o de entender as redes que se davam entre as terras e seus donos e que constituíram o que depois viria a ser denominada Villa Americana, traçando novos conflitos e novos fatos; o segundo, ainda em fase de elaboração, tem sido um esforço de perceber agentes outros nessa história que foram, muitas vezes, silenciados pelos jogos de poder imbricados no fazer histórico, como os negros eas mulheres.

A discussão sobre a história regional possui diversos autores e posicionamentos. Entre eles, buscamos abordar a questão a partir de uma perspectiva similar ao que propõe Erivaldo Fagundes Neves (2008, p. 28). Em suas palavras, "uma região resulta sempre da interveniência das redes de poderes econômicos, políticos, militares, eclesiásticos ou de segmentos sociais". Para esse pesquisador, a ideia de região se relaciona com o que se considera a "totalidade", por exemplo, um país ou o mundo, sendo essas categorias históricas. Dessa forma, ele acredita que se deve ressaltar as especificidades dos diferentes espaços, mas também chamar atenção para as "interconexões locais, regionais, nacionais, continentais e universais" (NEVES, 2008, p. 31). A metodologia comparativa, portanto, não deve sair de vista. É o que buscamos fazer ao estudarmos as dinâmicas econômicas e sociais da região de Campinas, mas também salientando aspectos da história nacional, como a escravidão.

Nesse sentido, este artigo é resultado dos últimos meses de pesquisa intensa a que nos dedi- 
camos e visa, predominantemente, trazer os primeiros passos de um trabalho historiográfico sobre a cidade de Americana. O enfoque encontra-se na Fazenda Salto Grande durante o período escravista e sua relação com o início da história americanense. Dessa forma, iniciamos com um breve debate bibliográfico com o intuito de localizar o leitor para, depois, apontar nosso percurso e as novas narrativas possíveis. Por fim, apresentamos um trabalho inicial e inédito de mapeamento da região no século XIX.

\section{Divergências sobre a história de Americana}

A história de Americana anda de mãos dadas com a história de Campinas, uma vez que aquela foi pertencente à Comarca desta até o início do século XX. Como destaca José Roberto do Amaral Lapa (1996), a consolidação da região se deu no século XIX, a partir da produção de açúcar e, depois, de café, sustentadas por uma ampla mão de obra escravizada, exploração esta que promoveria um enriquecimento de grandes proprietários e um processo de modernização e expansão da zona urbana na segunda metade do século.

Em entrevista (SIMSON, 2000), Lapa afirma que a narrativa de uma história de Campinas e região teve diferentes fases. Entre elas, encontra-se o período da primeira metade do século XXe início da segunda metade, na qual diversas obras foram escritas por memorialistas e cronistas, com grande destaque para o papel da imprensa na difusão desses textos. Para o historiador, esse trabalho historiográfico, ainda que com algumas incongruências metodológicas diante da pesquisa acadêmica que emerge a partir dos anos 1950 na região, não pode ser descartado. Trata-se, pelo contrário, de uma página importante na produção sobre a história da cidade, com a qual devemos ter crivos críticos de leitura, mas sem deixar de reconhecer sua riqueza.

Esses autores memorialistas e/ou cronistas escreveram obras consagradas sobre Campinas, reunindo também muitas informações sobre a constituição do território "entre rios", ou seja, da fazenda Salto Grande e da atual cidade de Americana. Dentre eles, dois nomes chamam atenção como referências principais nos materiais mais recentes publicados sobre a história americanense': Jolumá Brito e Celso Maria de Mello Pupo. Ambos, nascidos no início do sé-

1 Esses materiais são livros que compõem a historiografia regional mais recente sobre o início da história de Americana. Ressaltamos as obras Preservando nossa história (1999), Descobrindo Americana (2008), Americana e sua história (2010) e Carioba: um lugar, uma herança (2010), cujas referências completas se encontram no final deste texto. Eles utilizam, como principal referência, os autores Jolumá Brito e Celso Maria de Mello Pupo. Por esta razão, nos detemos, neste artigo, em analisar as obras desses dois pesquisadores. 
culo XX, publicaram livros sobre a história campineira por volta dos anos 1960, contudo, vale ressaltar que Brito, no final da década de 1950 , já possuía obras reconhecidas, falecendo em 1987, enquanto Pupo, por sua vez, tem novas publicações até os anos 1980. As especificidades e as divergências do conteúdo de suas pesquisas são frequentemente pouco abordadas e, portanto, nos propusemos a discuti-las, com o intuito de seguir o percurso da construção da historiografia americanense.

Americana teve seu início no século XVIII, com as ocupações e sesmarias nas terras do "Salto Grande", região compreendida entre a confluência dos rios Atibaia e Jaguari, no interior da Província de São Paulo. O jornalista Jolumá Brito explica, na obra História da Cidade de Campinas (1963, p. 97), o interesse de sesmeiros pela região:

Pelo fato de não existirem caminhos ou picadas abertas rumo à antiga Vila da Constituição foi que, talvez, nos fins do século XVIII, os antigos devastadores e bandeirantes de nossas matas e exploradores de sesmarias tivessem se interessado pela região que hoje é a cidade de Americana. Com a fundação da antiga aldeia de Santa Bárbara junto à Piracicaba, alargando-se territorialmente em direção à velha freguesia de Barreto Leme ${ }^{3}$ é que, acreditamos, tenha-se descoberto o grande "salto", que, pelas águas do rio Atibaia atingiram as proximidades da futura Capela fundada por dona Margarida da Craça Martins".

Segundo Brito (1963, p. 97), Antônio Machado de Campos, juntamente com Francisco de S. Paio, Antônio de S. Ferraz e André de Campos Furquim, "estão 'na paragem do Salto Grande, há mais de cinquenta anos (1771), ali cultivando e residindo, com fábrica de açúcar”'. O autor comenta que o engenho do Quilombo, de Antônio Machado de Campos, se localizava onde hoje é a cidade de Sumaré, "ao par do 'Salto Grande"” (BRITO, 1963, p. 97).

Contudo, o historiador Celso Maria de Mello Pupo pensa diferentemente a periodicidade das primeiras habitações na região. Ele defende que as datas das concessões de sesmarias não equivaleriam necessariamente à data de início das produções agrárias nesses locais. Na obra Campinas, município no Império (1983, p. 122), ele aponta que,

Temos que admitir a caducidade de várias concessões de sesmaria, que não foram povoadas e cultivadas, pois se repetem descrições em certas concedentes, sem provas de que os primeiros concessionários tenham permanecido no direito sobre elas. Como já dissemos, a data da sesmaria não indica o cultivo das terras, mas, apenas, a consolidação da propriedade com títulos regulares, podendo as culturas ser anteriores ou posteriores a esta consolidação, o mesmo se verificando com as escrituras de compra e venda.

2 Atualmente Piracicaba-SP.

3 Nossa Senhora da Conceição de Campinas, atual Campinas-SP.

4 Atual Paróquia Santa Bárbara, localizada no centro de Santa Bárbara D’Oeste-SP. 
Segundo o autor, "a produção açucareira em Campinas só surgiu na década de 1791-1800". Para ele os "recenseamentos provam a inexistência de produção de açúcar, sendo os sitiantes indicados [Dosé de Souza e Siqueira e Domingos da Costa Machado] produtores de aguardente, proprietários de engenhocas, para esta produção" (PUPO, 1983, p. 120). Vale ressaltar que a localização da região do Salto Grande era parte, então, da antiga Nossa Senhora da Conceição de Campinas, atual Campinas, e, de acordo com Pupo, "as primeiras sesmarias cultivadas e povoadas pelos sesmeiros foram obtidas pelos irmãos Filipe Néri Teixeira e Joaquim José Teixeira Nogueira, e mais o latifúndio comprado pelo cunhado deste último, Francisco de Paula Camargo" (PUPO, 1983, p. 122).

Desse modo, notamos discordâncias entre os autores quanto ao início do povoamento e da cultura da cana-de-açúcar na região do Salto Grande, bem como distintas formas de se pensar a geografia da região. Portanto, um primeiro conflito se consolida entre Brito e Pupo: se, para o primeiro, o território da atual Americana já era habitado por sesmeiros na década de 70 do século XVIII, para o segundo, a fixação de produtores de açúcar no local se daria apenas a partir do final do mesmo século. Seguindo o percurso dos dois pesquisadores, também são citadas referências diversas a donos de sesmaria na região do Salto Grande. De acordo com Jolumá Brito (1963, p. 97),

Existe mais referência a uma outra sesmaria que pertencera ao primeiro Domingos da Costa Machado, casado com a primogênita de Barreto Leme, ou fôsse ela d. Maria Barbosa do Rêgo que havia "cedido terras de sua sesmaria, parcialmente, antes de 1799 ao Cuarda-mor Manoel Teixeira Vilela e ao Alferes Antônio de Camargo Penteado ficavam localizadas entre os rios Atibaia e Jaguari, o 'Salto Grande' (hoje Americana), e foram obtidas juntamente com Antônio Vieira da Silva Pinto, João Antunes e Agostinho Luís Ribeiro, em 2 de abril de 1799".

Segundo Brito, portanto, o primeiro Domingos da Costa Machado ${ }^{5}$ teria cedido terras de sesmaria ao Guarda-mor Manoel Teixeira Vilela ${ }^{6}$ e ao Alferes Antônio de Camargo Penteado, em 1799. No entanto, para Pupo, em direção diferente a Brito, as terras não teriam sido doadas, mas vendidas por João Manuel do Amaral apenas a Manoel Teixeira Vilela. Em suas palavras:

Durante o governo do capitão-general Antônio Manuel de Castro e Mendonça, por ato seu, foi concedida uma sesmaria a João Manuel do Amaral, José Antônio do Amaral e Domingos da Costa Machado, abrangendo a confluência dos rios Atibaia e Jaguari, incluindo salto grande do primeiro. Os beneficiários não a povoaram até 1799 , quando o primeiro vendeu sua parte, por quinze mil réis, ao guarda-mor Manuel Teixeira Vilela. (PUPO, 1983, p. 148).

5 Constam, na mesma família, ao menos três gerações com o nome Domingos da Costa Machado, por isso, intitulamos o citado por Brito de "primeiro".

6 Optamos por essa grafia, com apenas um "L", para nos referirmos aos membros da família Vilela, seguindo o padrão de pesquisadores especialistas, como Maria Alice Rosa Ribeiro, citada ao longo deste trabalho. Alguns documentos históricos apresentam o sobrenome grafado de forma diferente, como "Vilella". 
Pupo defende que "a parte que coube a Domingos da Costa Machado, voltada para Oeste, constou de área na qual se fundou a fazenda, cuja sede, mais tarde, se tornou a indústria Carioba" (PUPO, 1983, p. 129). Para o autor, a venda de João Manuel do Amaral a Manuel Teixeira Vilela se daria também em 1799, mesmo ano em que Brito acreditava que as terras teriam sido doadas. Contudo, Pupo aponta que "não foi lavrada a escritura" da venda, tendo sido registrada em cartório apenas em dois de fevereiro de 1809 (PUPO, 1983, p. 148). Infelizmente, o historiador não referencia o documento, sendo pouco clara a localização da fonte onde consta essa informação.

Seguindo adiante, Pupo comenta que Manuel Teixeira Vilela teria construído, com mão de obra escravizada, a casa sede da Fazenda Salto Grande, descrita na obra como um dos "Grandes solares do Açúcar". Segundo o autor, a fazenda teria permanecido na família Teixeira Vilela até 1870 , quando comprada por Francisco de Campos Andrade. Sua obra foi uma das principais a consolidar a interpretação de que essas terras pertenciam aos Teixeira Vilela entre o início e o final do século XIX. Pupo pontua, porém, que as dimensões, nomenclaturas e imprecisões territoriais criaram confusões e embaraços historiográficos.

Assim, partindo de informações das obras desses dois cânones da pesquisa sobre a história de Campinas e região, Brito e Pupo, a historiografia americanense data e desenha o que seria o início do povoamento do território compreendido hoje como Americana. Entendendo sua história atrelada a sua formação geográfica, econômica e social, as especificações de compra, venda ou herança de terras, bem como dados territoriais, mostram-se essenciais para a compreensão do período e do que se considera o início de seu povoamento. Assim, nos propomos a estudar as fontes e referências da historiografia desse período, elaborando um estudo genealógico da Fazenda Salto Grande.

Para tanto, inspiramo-nos no trabalho coordenado por Suzana Barretto Ribeiro, Sesmarias, Engenhose Fazendas: Arraial dos Souzas, Joaquim Egídio, Jaguary (1792-1930) (2016). Em parceria com diversos estudiosos, a pesquisadora propôs uma revisão interdisciplinar sobre a história da cidade de Campinas desde o século XVIII, retomando as diversas documentações acerca das terras e seus proprietários, até culminar na urbanização da região. Ainda que Americana fosse parte da mesma comarca na época, porém, o estudo tem seu recorte geográfico demarcado nas áreas da atual Campinas, deixando de lado uma análise mais aprofundada do baixo Atibaia, o que propomos nesta pesquisa.

\section{Seguindo as trilhas da historiografia americanense}

Como Marc Bloch (2001) pontua já na década de 1940, a pesquisa histórica não nos permite um acesso a uma verdade absoluta ou a uma origem bruta dos fatos. A leitura das fontes históri- 
cas, portanto, deve perpassar uma postura crítica do pesquisador. Nesse sentido, procuramos por documentos que permitissem entender o percurso de uma história da Fazenda Salto Grande e de Americana sob um prisma crítico, tentando perceber a construção das narrativas mais consolidadas. Buscando pelos caminhos que teriam constituído a história da cidade, nos deparamos com os' volumosos inventários da família Teixeira Vilela, armazenados no Centro de Memória da Unicamp como parte do acervo do Tribunal de Justiça de São Paulo na Comarca de Campinas.

Deacordo com a produção historiográfica, o primeiro dono da fazenda seria Manoel Teixeira Vilela, falecido em 1820. Seu inventário, porém, não foi encontrado, como também pontua a historiadora Maria Alice Rosa Ribeiro (2015, p. 541). O suposto segundo dono das terras seria seu filho Antônio Manoel Teixeira, seu herdeiro, assim como herdeiro de seu irmão José Manoel Teixeira Vilela, falecido em 1846. Seguindo o percurso, nos deparamos com o inventário de Antônio, que data de 1852 , ainda que seu falecimento tenha se dado em 1850. Nele, podemos observar a riqueza da família, com um grande número de terras listadas: Engenho da Cachoeira, Sítio da Lagoa, terras em Parnaíba, Sítio Bom Fim, Sítio da Boa Esperança, Fazenda de Santa Bárbara, Fazenda do Paraná, Morro Alto, Saltinho, Sítio da Califórnia e Sítio do Jaguary. Ou seja, ainda não há a listagem de qualquer fazenda denominada Salto Grande.

Antônio Manoel Teixeira deixa muitas dívidas e passa a seu herdeiro Francisco Teixeira Vilela - o suposto terceiro dono de Salto Grande - apenas as fazendas Morro Alto e Cachoeira. Suas propriedades, porém, também se estendiam a mais de quatrocentos escravos, quantidade muito grande para a época, colocando-o como um dos maiores proprietários de cativos na região.

Francisco Teixeira Vilela, porsua vez, falece em 1873, ainda mais endividado do que o pai, deixando a família sem qualquer propriedade. Em seu inventário, constam as terras Morro Alto e Cachoeira, herdadas do pai, Santa Maria, grande fazenda na região da atual Campinas, e o Sítio Areia Branca. Entre suas propriedades - todas entregues aos credores - também constava uma grande lista de escravos. De acordo com Maria Alice Rosa Ribeiro, Francisco falece subitamente, em um momento no qual ainda não havia colhido frutos de altos investimentos (RIBEIRO, 2015, p. 554).

Como comenta a autora em seu estudo sobre a família Teixeira Vilela, há uma hipótese levantada por alguns estudiosos da região de Campinas de que a fazenda Salto Grande seria, na verdade, a fazenda Cachoeira dos inventários citados. Parte dessa hipótese pareceu encontrar respaldo nas obras de Hércules Florence, em especial em suas aquarelas e seus nanquins produzidos em 1834. Na legenda da imagem, escrita pelo pintor, ele diz: "Vue Du sitio d’Antonio Manuel Teixeira à 5 léguas de S. Carlos, Prov de St Paul. (Anto MI Teixra) sur la rive Jaguari" (LEMOS, 1999, p. 48). Nesse sentido, ele apresenta a vista da sede da fazenda de Antonio, sem citar Salto Grande.

Com as novas possibilidades apresentadas a partir desta pesquisa, levantamos a hipótese de que 


\section{Dossiê}

as imagens poderiam não retratar o sobrado de Salto Grande. Carlos Lemos (1999), por exemplo, a partir da observação da arquitetura da casa na pintura e do prédio remanescente em Salto Grande, comenta que Florence teria "errado" o número de janelas do sobrado. Segundo ele, o estilo arquitetônico desse casarão seria "ortodoxo", ou seja, um piso térreo de serviços e, acima, uma moradia' isolada. Ainda de acordo com o autor, foram poucas as construções desse tipo no meio rural paulista e o único que teria sobrevivido ao tempo teria sido justamente o da fazenda Salto Grande, localizada em Americana, interior do Estado de São Paulo.

Todavia, há outros exemplos de sobrados no estilo do representado por Florence. No livro Campinas, Município no Império, de Celso Maria de Mello Pupo (1983, p. 120-156), por exemplo, constam o Solar Teixeira Nogueira e a Fazenda Bonfim com prédios na forma de grandes paralelepípedos. Portanto, apesar de existirem poucos sobrados no estilo de construção do representado na aquarela de Florence, havia imóveis parecidos, e, dada a sobrevivência do casarão de Salto Grande e a associação de sua propriedade aos Teixeira Vilela, é possível que tenha ocorrido uma confusão na interpretação da imagem.

Imagem 1 - Engenho da Caxoeira, a 5 léguas de S. Carlos, Província de S. Paulo (1835), de Hércules Florence. Nanquim sobre papel, $25,9 \times 37,7 \mathrm{~cm}$.

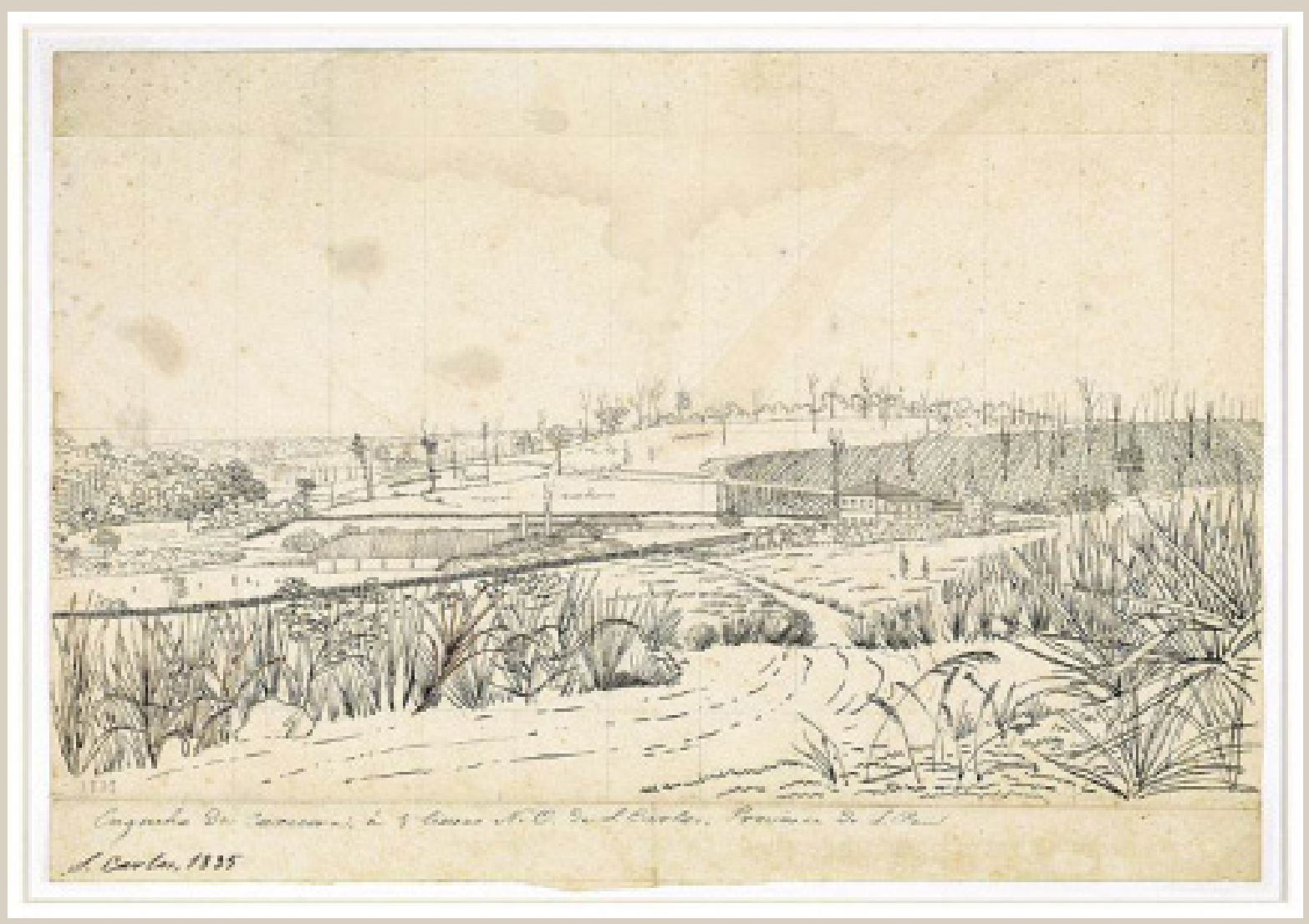

Fonte: Coleção Cyrillo Hércules Florence, São Paulo. Fotografia de Jorge Bastos. 
A ideia de Cachoeira e Salto Grande serem a mesma propriedade nos chamou atenção, já que, na historiografia de Americana, a segunda fazenda é posta como denominada dessa forma desde o princípio. Segundo os inventários, pelo menos até a morte de Francisco Teixeira Vilela, em 1873, ainda é citado o nome Cachoeira para a propriedade. Dessa forma, o choque entre as fontes escritas, iconográficas e a bibliografia permitiria a hipótese de que Salto Grande e Cachoeira não seriam a mesma fazenda, mas terras diferentes.

Caminhando para o quarto suposto dono da fazenda Salto Grande, notamos a ausência do inventário de Francisco de Campos Andrade, que não era herdeiro dos Vilela, mas teria adquirido as terras por compra. No entanto, pudemos encontrar o inventário de sua esposa, Barbara Paes de Barros Campos, falecida em 1888. Nele, localizamos a fazenda Salto Grande, bem como outras terras também pertencentes ao seu marido, denominadas Santa Bárbara. No texto,

A leitura dos documentos, portanto, parecia não levar à narrativa esperada a partir dos trabalhos historiográficos sobre Americana, uma vez que os inventários dos Vilela sugeriam que as terras de Salto Grande não pertenciam a essa família ou eram denominadas de outra forma. não constam escravos como bens, sendo executado no dia 9 de maio, quatro dias antes da assinatura do documento que viria a proclamar a abolição da escravidão no Brasil.

A leitura dos documentos, portanto, parecia não levar à narrativa esperada a partir dos trabaIhos historiográficos sobre Americana, uma vez que os inventários dos Vilela sugeriam que as terras de Salto Grande não pertenciam a essa família ou eram denominadas de outra forma. Essa situação nos intrigou, já que a narrativa consolidada não citava tais problemas nas fontes. Isso nos leva à segunda parte da pesquisa.

\section{Possíveis caminhos até Salto Grande}

Diante das dúvidas deixadas pelo percurso de pesquisa sobre a família Teixeira Vilela, recorremos ao Arquivo do Estado de São Paulo, onde tivemos acesso ao Registro de Terras da Província de São Paulo referente à Comarca de Campinas, feito entre 1854 e 1857. Nessas fontes, 
encontramos duas ocorrências de "Salto Grande". A primeira se refere a uma "Fazenda Salto Grande", no registro de número 69, de 14 de agosto de 1855 , no qual o Alferes José de Campos Penteado assume a propriedade das terras entre o rio Jaguari e o rio Atibaia, fazendo divisa com o sítio denominado Saltinho. Nesse sentido, ele cita seus donos anteriores e diz que as terras possuem um engenho de açúcar, pertencente a ele mesmo, e dois de café, pertencentes aos seus filhos Antônio de Camargo Campos, José de Campos Penteado Junior e Francisco de Campos Andrade, como no trecho abaixo:

O Sítio de Salto Grande é propriedade do Alferes José de Campos Penteado e suas confrontações são as seguintes $=$ Da beira do Rio Jaguary por onde se verificará a divisa com o sítio denominado Saltinho pertencente a Felippe Antonio Franco partirá um rumo atéo Rio Atibaia, e descendo rio abaixo o rio é divisa até o ponto da divisa com o sítio do falecido Capitão José Ignácio de Camargo Penteado, hoje de seus herdeiros aí deixará o rio e seguirá em rumo reto até sair na estrada velha de Limeira seguindo mesma estrada até o espigão que serve de divisa com José de Campos Penteado Junior e Francisco de Campos Andrade e seguindo o mesmo espigão divisa com Dona Anna Cândido Campos Machado até frontear um vallo da mesma então descerá a rumo até o vallo adiante até o rio, e pelo rio acima até encontrar o lugar de onde é e tem de partir a divisa do sítio Saltinho como acima fica dito. (...) Contém dentro deste sítio três estabelecimentos, sendo um de engenho de fabricar açúcar pertencente ao proprietário. Dois de café sendo um pertencente a Antônio de Camargo Campos e outro a José de Campos Penteado Junior em sociedade com seu irmão Francisco de Campos Andrade - Todos filhos do proprietário; cujo sítio acima declarado pode regular mais ou menos meia légua em quadra. Campinas 16 de agosto de mil oitocentos e cinquenta e cinco (REGISTRO DE TERRAS DA PROVÍNCIA DE SÃO PAULO, 1855, s. n.).

Já na segunda ocorrência, de 21 de dezembro de 1855, José de Campos Penteado Junior e Francisco de Campos Andrade descrevem os limites das suas terras chamadas de "Sítio do Salto Grande", ligada à propriedade do pai. Nesse trecho do registro de número 220 , os dois filhos de José de Campos Penteado tratam dos limites das terras de sua propriedade, fazendo divisa com as terras do engenho do pai e de Domingos Leite:

O sítio no bairro do Salto Grande é freguês de Campinas, e é propriedade de Jose de Campos Penteado Junior e Francisco de Campos Andrade, suas confrontações são as seguintes; Principiando no canto de uma cerca por uma linha reta até encontrar com terras de Domingos Leite e aí segue rumo direto até embicar num marco de pedra que se acha na beira do caminho de Antônio Ferreira da Silva, seguindo pelo caminho até um pau de batata arcado, desse pau de batata vai em linha reta a um cipó que tem no caminho que foi de Manoel Alvares Machado, daí segue pelo caminho como quem volta para o mesmo sítio até a beira de uma capoeira alta, da beira dessa capoeira sêgue uma linha reta a sair no caminho do falecido Major Domingos, ficando na encruzilhada dum caminho antigo que ia para Santa Barbara, desta encruzilhada 
volta pelo caminho como quem vem para o sítio - procurar o espigão do outro lado da estrada, segue por ela até sair na estrada velha de Limeira e segue a estrada até sair no caminho velho de Dona Certrudes até a beira de um capão de mato virgem aí entra por uma picada até encontrar com uma carreira de bananeiras acabando as bananeiras segue pelo espigão divisando com Domingos Leite e José de Campos Penteado (Pai dos proprietários) até dar na divisa com o Major Domingos, por onde se verifica por haver parte no sítio do finado Major Domingos, pertencente aos proprietários que ainda estão em divisas, porém tem que seguir essa divisa até dar no marco de pedras como acima se declara, sua propriedade ou sítio terá mais ou menos um quarto em quadra. Campinas vinte e um de dezembro de mil oitocentos e cinquenta e cinco = Campos Junior e Irmão. (REGISTRO DE TERRAS DA PROVÍNCIA DE SÃO PAULO, 1855, s. n.).

A partir dessas informações, sustenta-se uma hipótese de que as terras de Salto Grande, já em 1855, pertenciam provavelmente a Francisco de Campos Andrade, colocado como último dono da fazenda antes da abolição da escravidão pela historiografia local. Mais do que isso, porém, nota-se sua sociedade com o irmão, localizada dentro da propriedade de seu pai, José de Campos Penteado. Dessa forma, abre-se uma nova possibilidade de narrativa histórica que contrariaria as ideias mais consolidadas sobre a região, isto é, a de que as terras de Salto Grande pertenciam à família Teixeira Vilela. Essa ideia é corroborada pela ausência da fazenda nos inventários dessa família e pela ocorrência, no Registro de Terras, de uma propriedade de mesmo nome e localização como pertencente aos Campos Penteado.

Para analisarmos essas hipóteses, recorremos novamente ao Centro de Memória da Unicamp e ao acervo do Tribunal de Justiça de São Paulo na Comarca de Campinas. Nesse sentido, fizemos o percurso inverso, partindo de Francisco de Campos Andrade, nome já conhecido a partir da leitura dos trabalhos locais, para buscar a possível ligação geracional de sua família com as terras da região.

Como já comentado, não foi possível localizar o inventário de Francisco de Campos Andrade, contudo, consta no arquivo o inventário de Barbara Paes de Barros Campos, sua esposa, de 1888. No documento, são citadas as terras de Salto Grande e a fazenda Santa Bárbara e listadas as benfeitorias e bens de cada uma das propriedades. Dessa forma, observamos uma descrição das construções existentes na fazenda e seus valores estimados, a exemplo da "casa de morada de sobrado e quadrado anexo", avaliada em "quatorze contos de reis" ou a "caza de moinho de fecha", de "um conto de reis" (INVENTÁRIO DE BARBARA PAES DE BARROS CAMPOS, 1888, p. 30-31).

Seguindo a árvore genealógica da família, como consta no Registro de Terras da Comarca de Campinas, buscamos pelo inventário do pai de Francisco de Campos Andrade, o Alferes José 
de Campos Penteado. Falecido em 1860, o documento cita a fazenda Salto Grande como parte de seus bens:

Um sítio denominado Salto Grande com casas de sobrado, senzalas, engenho de moer cana tocado por água, com todos os seus pertences, engenho de serra, tenda de enchugar açúcar, pachões e todas as suas benfeitorias, com todas as terras que lhe pertencem, compreendendo as em que estão arranhados os herdeiros Antônio e Francisco, bem como a estalagem e suas terras, tudo por 111:000\$000 (INVENTÁRIO DE JOSÉ DE CAMPOS PENTEADO, 1860, p. 11).

O inventário também possui uma extensa lista de escravos. A partir desse documento e de testamentos, também pudemos notar que José foi casado uma primeira vez com Rita Antonia da Silva Serra, falecida em 1838, e, depois, com Anna Francisca de Andrade. No inventário, constam entre seus familiares Francisco de Campos Andrade, Floriano de Camargo Campos, Antonio de Camargo Campos, José de Campos Penteado, Anna Elidia de Campos, Candido da Silva Serra e Anna de Campos Paes.

Essas informações trazidas pelo inventário de José de Campos Penteado, de 1860, dialogam com os dados do Registro de Terras da Comarca de Campinas, de 1855, contrariando também a hipótese de que a propriedade das terras de Salto Crande seria dos Vilela na mesma época. Segundo o Registro, Salto Grande aparece uma vez como propriedade de José e, outra, como um sítio nas mesmas terras onde seus herdeiros mantinham um engenho, assim como consta no trecho do inventário supracitado.

Na obra História de Limeira, de Reynaldo Kuntz Busch (1967, p. 53), o autor também comenta que, em uma carta de 28 de junho de 1823, existente no Arquivo Público do Estado, o Engenho de Salto Grande é posto pelo próprio José de Campos Penteado como sua propriedade, descrevendo que suas terras são próximas a de nomes como Alferes Antonio Furquim, Antonio Manoel Ferreira, Capitão José Pedrozo da Silva, Nicolau Conçalves, Capitão Domingos ${ }^{7}$ e Joaquim Ferreira. É importante perceber que há um conflito entre esse estudo e obras canônicas sobre a história de Campinas - como as escritas por Jolumá Brito e Celso Maria de Mello Pupo-, que afirmavam a propriedade de Salto Grande pela família Vilela.

Dando um último passo para trás na árvore genealógica da família de Francisco de Campos Andrade, buscamos também pelo seu avô Antonio de Camargo Penteado, pai do Alferes José de Campos Penteado. No seu inventário, de 1812, Antonio lista entre seus bens, além de escravos, terras entre os rios Jaguari e Atibaia, fazendo divisa com Manuel Teixeira Vilela:

7 Não há o nome completo citado no trecho. 
Por humas terras pertencentes ao erdeiro ]osé de Campos na forma da verba dos [palavra ilegível] entre os rios Jaguary e Atibaia, na paragem denominada corrego da Jacutinga, que rio acima do Jaguary, confina com terras do Cuarda-mor Manoel Teixeira Vilella, com hum quarto de testada e meia légua de certao que foram vistas e avaliadas pellos mesmos avaliadores pela quantia de cem mil reis com que sahe (INVENTÁRIO DE ANTONIO DE CAMARGO PENTEADO, 1812, p. 18).

Vale ressaltar que, tanto no inventário de Antonio, de 1812, quanto no Registro de Terras, de 1855, são citadas as terras vizinhas à Salto Grande, informações importantes para um mapeamento da região na época. No primeiro caso, ela faria divisa com uma propriedade de Manoel Teixeira Vilela e, no segundo, com Felippe Antônio Franco. Isso poderia significar que as terras vizinhas à Salto Grande teriam mudado de proprietário.

Em 1850, no inventário de Antonio Manoel Teixeira, consta Saltinho como sua propriedade. Antonio, porém, falece com muitas dívidas, comojá comentado, e passa para seu herdeiro Francisco Teixeira Vilela apenas as fazendas Morro Alto e Cachoeira. No Registro de Terras, de 1855, Felippe Antônio Franco, no registro de número 153, é posto como dono de uma propriedade denominada Saltinho, que se localizava ao lado de "Morro Alto sítio de Francisco Teixeira Vilella", que "divisadas pelos Rios Attibaia e Jagyuary pela margem delimita com a Fazenda do Alferes José de Campos Penteado" (REGISTRO DE TERRAS DA PROVÍNCIA DE SÃO PAULO, 1855, s. n.).

Isso poderia significar que essas terras vizinhas de Salto Grande se refeririam à fazenda Saltinho, pois, se na morte de Antonio Manoel Teixeira, em 1850, as terras não passam a seu filho e são perdidas pela dívida, em 1855, elas já poderiam pertencer a Felippe Antônio Franco, como notado no Registro de Terras. Para além dessas informações, Felippe também descreve a divisa de suas terras com José de Campos Penteado e comenta sobre a vizinhança com Francisco Teixeira Vilela, proprietário de Morro Alto, terra que herdou

A partir da leitura e das novas narrativas que essas documentações levantaram, foi possível um primeiro esforço para mapeara região de Americana e as fazendas que compunham seu território em meados do século XIX. Trata-se de um trabalho inédito, ainda em construção, baseado na hidrografia anterior ao represamento do rio Atibaia, no século XX. do pai após o pagamento das dívidas. Essa leitura dos documentos nos leva a pensar que a hipótese do pertencimento de Salto Grande à família Vilela teria se conformado a partir da proximidade das terras e a confusão das datas, uma vez que se mostra necessária a confrontação dos documentos para perceber as ligações. 


\section{Reflexões finais: Salto Grande e a escravidão}

A partir da leitura e das novas narrativas que essas documentações levantaram, foi possível' um primeiro esforço para mapear a região de Americana e as fazendas que compunham seu território em meados do século XIX. Trata-se de um trabalho inédito, ainda em construção, baseado na hidrografia anterior ao represamento do rio Atibaia, no século XX. A partir da localização geográfica assinalada nos inventários e no Registro de Terras, assim como dos rios Atibaia e Jaguari e do córrego ]acutinga, o mapeamento permite observar as fazendas que percorrem essa pesquisa, em especial Salto Grande, destacada em listrado.

\section{Imagem 2 - Mapa da região de Americana em 1855}

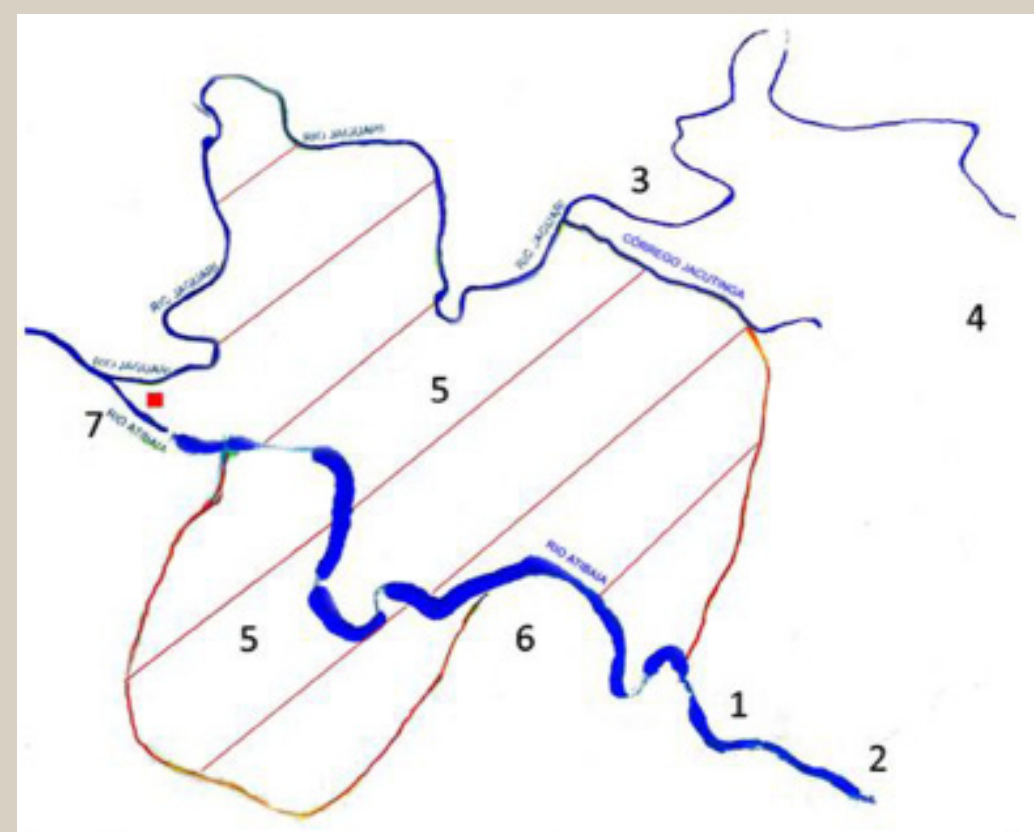

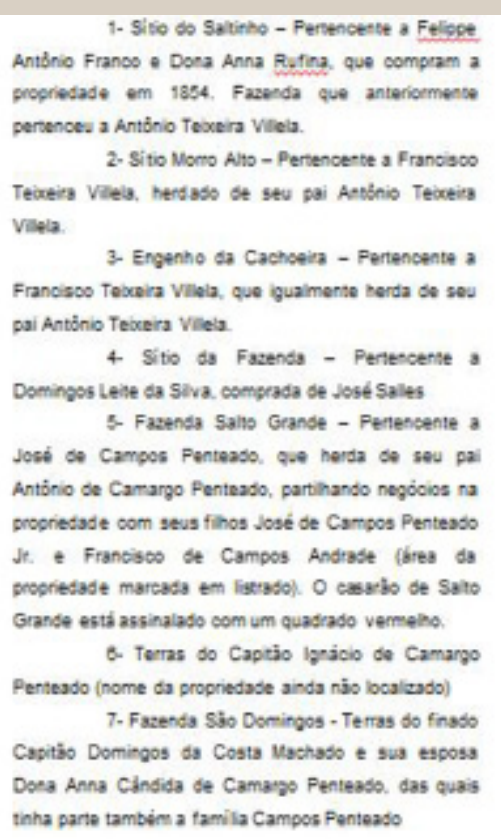

Fonte: Elaborado pelos autores

Há ainda, porém, muitas estradas a serem traçadas quando falamos dessa região. Se é possível seguir alguns passos de proprietários de terras pelos documentos oficiais da época, nem por isso se torna fácil entender os processos que se deram na região e conformaram a cidade, em especial acerca do trabalho escravo. Contudo, abrindo novas hipóteses sobre as demarcações de terras, também notamos outras possibilidades de documentações que jogam luz à história da resistência dos escravizados na região.

A pesquisa referente à escravidão em Campinas - já amplamente estudada por nomes como Peter Eisenberg (1989) e Robert Wayne Slenes (2011) -, nas terras da comarca onde nasceria 
a futura Americana, mostram que ela estava presente desde as primeiras ocupações de terras. Como já comentado, há diversas referências ao uso de mão de obra escrava por famílias como os Vilela ou mesmo no período do início da industrialização da região, no final do século XIX. Nas documentações estudadas durante a pesquisa, é perceptível como os escravizados eram sinal de poder entre os senhores de terra e fundamentais para seu enriquecimento. Antônio Manoel Teixeira, por exemplo, tem em seu inventário uma lista na qual constam mais de quatrocentos escravizados em sua propriedade. Na família Campos Penteado, a grande quantidade de escravizados também chama atenção nos documentos: no inventário de José de Campos Penteado, por exemplo, constam mais de duzentos cativos.

Entretanto, na cidade de Americana, essa história é muitas vezes esquecida ou mesmo apagada, dando-se maior destaque à imigração italiana, norte-americana ou de outras das várias nacionalidades europeias, fortalecendo um discurso de que essa foi a mão de obra essencial para a formação sócio-econômica, cultural e mesmo étnica da região. É comum encontrar uma narrativa de exaltação dos colonos, afirmando, por exemplo, que "superaram tudo com valentia, tornando-se posteriormente os industriais, comerciantes e seus descendentes, profissionais liberais, sobrepujando todas as barreiras e restrições a eles impostas" ou que tinham uma cultura rica e muitas técnicas de trabalho, favorecendo o desenvolvimento econômico brasileiro (COBBO, 1999, p. 28).

Percebe-se que escassamente são utilizadas as mesmas categorias para se referir aos escravizados, como a ideia de riqueza cultural. Notamos, portanto, a existência de pesquisas históricas que não abordam as violências da escravidão no início da formação de Americana, mas também que não analisam esses sujeitos históricos como essenciais para a emergência da região. É interessante notar que, nesse sentido, os estudos sobre a cidade parecem se afastar das inúmeras pesquisas sobre a história de Campinas e a mão de obra escravizada, deixando de lado o pertencimento da Villa Americana às mesmas lógicas econômicas da comarca da qual era parte.

As primeiras ocupações na região de São Carlos, de onde depois se desmembraria Campinas, constam do ano de 1793. Segundo os estudos do pesquisador Peter Eisenberg, disponíveis no acervo do Arquivo Edgard Leuenroth, na Universidade Estadual de Campinas, a estimativa de habitantes de São Carlos em 1798 - isto é, na região que abrangia onde se localizariam posteriormente Campinas e Americana - era de 701 pretos e mulatos cativos em um total de habitantes de 2508 , ou seja, os escravizados contavam $28 \%$ da população. Em 1829, apenas trinta anos depois, a região já contava com 4263 pretos e pardos cativos, sendo $56 \%$ da população total de 7627 habitantes. Por fim, em 1854, na já chamada comarca de Campinas, o total de 
escravizados é de 15285 enquanto a população total é de 32011 pessoas, portanto, a porcentagem de cativos é de $47,74 \%$ da Comarca.

Tem-se com esses estudos uma ideia da importância desses escravizados na história da região, perceptível pelo grande crescimento da população de cativos. Um levantamento prévio de documentações nos arquivos Martha Watts, em Piracicaba-SP, no Centro de Memória da Unicamp e no Arquivo Público do Estado de São Paulo apresentam uma série de listagens e processos judiciais de escravizados, mostrando não só violências como também as possíveis agências desses sujeitos históricos.

Por fim, as histórias que buscamos analisar sobre Americana no século XIX confluem para a formação do que viria a ser a urbanização da cidade e marcá-la até seu presente. É a partir das terras de Salto Grande que, no final do século XIX e mais fortemente no século XX, se instalam as fábricas de tecido Carioba, vila operária que garantiu o apelido de "Princesa Tecelã" ao município. Estudar a história de Americana a partir da busca das fontes históricas é um desafio que apenas começou, abrindo novos caminhos que os Historiadores Independentes de Carioba estão dispostos a trilhar.

\section{Referências}

BLOCH, Marc. Apologia da história on O oficio de historiador. Tradução de André Telles. Rio de Janeiro: Jorge Zahar, 2001.

BRITO, Jolumá. História da Cidade de Campinas, v. 18. Campinas: Editora Saraiva, 1963.

BUSH, Reynaldo Kuntz. História de Limeira. Limeira: Prefeitura Municipal, 1967.

DADOS DE POPULAÇÃO DE VILA DE SÃO CARLOS E DE CAMPINAS. Acervo Peter Eisenberg, pasta 609.

DADOS DE POPULAÇÃO, PRODUÇÃO E OCUPAÇÃO EM CAMPINAS, 1799 À 1829. Acervo Peter Eisenberg, pasta 611.

DADOS DE POPULAÇÃO E ETNIA, DE 1708-1824. Acervo Peter Eisenberg, pasta 612.

EISENBERG, Peter. Homens Esquecidos: escravos e trabalhadores livres no Brasil - Séculos XVII e XIX. Campinas: Editora da Unicamp, 1989.

COBBO, Célia (Org.). Preservando nossa história: Americana. Americana: Ed. Pallas Athena, 1999. 
INVENTÁRIO DE ANTONIO DE CAMARGO PENTEADO, $7^{\circ}$ Of., Cx. 11, Proc. $n^{\circ} 280,1812$.

INVENTÁRIO DO COMENDADOR ANTONIO MANOEL TEIXEIRA. $7^{\circ}$ Of., CX. 162 , Proc. $n^{\circ} 2899,1852$.

INVENTÁRIO DEJOSÉ DE CAMPOS PENTEADO, $1^{\circ}$ Of., Cx. 155, Proc. n³284, 1860.

INVENTÁRIO DO COMENDADOR FRANCISCO TEIXEIRA VILELLA. $1^{\circ}$ Of., CX. 257, Proc. $\mathrm{n}^{\circ} 4359,1873$.

INVENTÁRIO DE BARBARA PAES DE BARROS CAMPOS, $3^{\circ}$ Of., Cx. 370, Proc. n 7512, 1888.

LAPA, José Roberto do Amaral. A cidade: os cantos e os antros: Campinas 1850-1900. São Paulo: Edusp, 1996.

LEMOS, Carlos A. C. Casa Paulista: história das moradias anteriores ao ecletismo trazido pelo café. São Paulo: Editora Universidade de São Paulo, 1999.

NEVES, Erivaldo Fagundes. História e região: tópicos de história regional e local. Ponta de Lança. São Cristóvão, v.1, n. 2, p. 25-36, abr. 2008. Disponível em: <https://seer.ufs.br/index.php/ pontadelanca/article/view/3146/0>. Acesso em: 08 abr 2019, às 16 h47.

POPULAÇÃO DE CAMPINAS - SEXO E CONDIÇÃO LEGAL; POPULAÇÃO EM GERAL - \% VARIDADE 20-49 OU 21-50. Acervo Peter Eisenberg, pasta 587.

PUPO, Celso Maria Mello. Campinas, município no Império. Fundação e Constituição; usos familiares. São Paulo: Imprensa Oficial do Estado, 1983.

PUPO, Celso Maria Mello. Campinas, seu berço e juventude. Campinas: Academia Campinense de Letras, 1969.

REGISTRO DE TERRAS DA PROVÍNCIA DE SÃO PAULO, COMARCA DE CAMPINAS, 1854-1857. Microfilme ${ }^{\circ} 3006$.

RIBEIRO, Maria Alice R. Música no ar... Cachoeira, Santa Maria, Morro Alto e Saltinho. Teixeira Vilela, Hercule Florence e Carlos Comes, Campinas, século XIX. Anais do Museu Paulista, São Paulo, v. 24, n. 2, p. 53-75, maio 2016. Disponível em: $<$ http://www.scielo.br/scielo.php?script=sci_arttext\&pid=S0101-47142016000200053>Acesso em:27jul.2018.

RIBEIRO, Maria Alice R. Riqueza e endividamento na economia de platation açucareira e cafeeira: a família Teixeira Vilela-Teixeira Nogueira, Campinas, São Paulo, século XIX. Estudi.ecom. São Paulo, v. 45, n. 3, p. 527-565, jul. 2015. Disponível em:<http://dx.doi.org/10.1590/0101-416145353mar>. Acesso em: 27 jul. 2018.

RIBEIRO, Maria José, F. A.; FERREIRA, Melquesedec. Americana e sua história. Americana Prefeitura Municipal de Americana, 2010.

RIBEIRO. Maria Jósé, L. V. (Org.). Descobrindo Americana: um grande salto. Americana: Prefeitura Municipal de Americana, 2008. 
Dossiê

Cidades Imaginadas,

Cidades Reais

RIBEIRO, Suzana Barreto (coord). Sesmarias, Engenhos e Fazendas; Arraial de Souzas, Joaquim Egydio, Jaguary (1792 - 1930). Campinas: Novo Mundo, 2016.

SIMSON, Olga Rodrigues de Moraes von (org.).O garimpeiro dos cantos e antros de Campinas : homenagem a José Roberto do Amaral Lapa. Campinas: Editora da Unicamp, 2000.

SLENES, Robert Wayne. Na senzala, uma flor - esperanças e recordações na formação da família escrava: Brasil Sudeste, século XIX. 2. ed. Campinas: Editora da Unicamp, 2011.

STOCK, Suzete de Cássia, V. Carioba: um lugar, uma herança. São Paulo: Ed. Lexia, 2010.

Recebido em: 12 de fevereiro de 2019

Aprovado em: 22 de maio de 2019

172

Resgate-Rev. Interdiscip. Cult., Campinas, v. 27, n. 1 [37], p. 155-172, jan./jun. 2019-e-ISSN: 2178-3284 